\title{
SWINE, SHEEP AND GOATS \\ IN THE ORIENT
}

Important Factors in the Animal Industries of China Which Show Need for the Application of Modern Principles of Animal Breeding-Average Village Farmer Knows Little About Proper Feeding and Selection of Best Types

C. O. Levine

Associate Professor of Animal Husbandry, Canton Christian College

$I^{N}$ N CHINA the swine industry is next in importance to that of raising poultry. It is difficult to ascertain the number of pigs raised each year in that country, and all estimates are little more than rough guesses. Prof. King, in his interesting book, "Farmers of Forty Centuries," estimates the number of pigs in Shantung at 25,000,000, a number equal to one for each inhabitant in that province. A conservative estimate of pigs raised annually in China would be $100,000,000$. At the low price of $\$ 12$ (Mex.) ${ }^{1}$ each, which is the amount received for the average pig sold on the market, the annual pig crop would have a value of $\$ 1,200,000,000$ (Mex.). During the years from 1915 to 1917 the average annual exports of swine exceeded the imports to the amount of 2,000,000 taels. ${ }^{2}$ Most of the hogs exported were sent to Kongkong and to Russia. A large number of those sent to Hongkong are butchered and converted into lard, which is then shipped to Liverpool.

The exportation of bristles, a byproduct of the swine industry, is of considerable importance, the amount of this product from Shantung province alone amounting to about 500,000 pounds a year. The prices paid by exporters for cleaned, sorted and dried bristles varie; from $\$ 20$ to $\$ 220$ (Mex.) for 100 pounds.

DESCRIPTION OF CHINESE LARD HOGS

Hogs in different parts of China vary considerably in size and type. The com- mon lard hog is found in most places of the South. They range in color from nearly white to black, or black with white points. In some localities the pigs' ears are large and pendulent, while in others they are small and erect Then again, these two types may be found in the same community.

A peculiar characteristic of the lard hogs of China is their straight tails. They do not have the "kink" which is characteristic of the tails in modern breeds. It is this hog that was largely used in the early development of European breeds. The meat is of good quality and cures fairly well. As a rule the hogs are fine-boned and smooth; those with wrinkled sides are seldom seen. They are slow in maturing. Twelve hogs at the Canton Christian College in 1917 made an average gain, at six months of age, of about 0.65 of a pound a day on full feed. When one year old they usually weigh from 200 to 250 pounds. The average dressing per cent of thirty-two hogs butchered at the College in 1917 and 1918 was $72.5 \%$. The chief objection to this hog is its low back, scant hams, large belly, low dressing percentage, and weak pasterns, which easily break down in the animal that is being fattened.

\section{CHINESE METHODS OF RAISING PIGS}

Most farmers who raise hogs keep from one to five or six brood sows. The litters are large. A sow is supposed to be able to nurse at least ten pigs, which seems to be the average 
number in the Canton region, although as many as fifteen are frequently seen with one sow.

During the day the sow and pigs roam at will in the narrow, stone streets of the villages, picking up what edible garbage they can find. Sometimes, however, the sow is muzzled when thus turned out with her family of pigs.

Pigs are usually castrated and spayed when they are six to ten weeks old and still sucking, although animals weighing as much as 100 pounds are sometimes thus operated on. The Chinese consider it just as necessary to spay gilts as to castrate boars. Meat from unspayed gilts is somewhat coarser than that from spayed animals, and better growth is also obtained by spaying.

Both operations are considered art, and practiced only by a few experts. Spaying is never attempted by the farmer himself, and castration only when the services of an expert cannot be secured. A professional usually has an apprentice along to assist him. After a time the apprentice performs the operations himself and becomes an expert provided he can work rapidly enough. The methods used are the same as those in western countries. Spaying, however, is somewhat different.

No disinfectants are used, nor is the operator particular about the pig, or his own hands being clean. No doubt many of the few losses which do occur are due to this lack of sanitary precaution on the part of the operator, and because of the fact that feed is not reduced either before or after the operation. In the fall of 1918 the service of a local hog "veterinarian"-_if he should be referred to by such an honorable title-was secured by the College, and four gilts weighing about forty pounds each were spayed. The operator was allowed to use his own methods. No disinfectants were used, nor was the amount of feed reduced, either before or after the operation. The operations were successful in every case. Very little discomfort was shown by the pigs after the operation, and they did not get "off feed."

\section{HOG FEEDING PLANTS IN CONNECTION WITH DISTILLERIES}

Hog feeding plants, feeding from 100 to 300 hogs at a time, are usually found in connection with rice wine distilleries. In Honam, south of Canton, there is a representative plant of this kind. This is a rice wine distillery, with a hog feeding plant run in connection. The writer last visited the plant on November 2, 1918. At that time about 200 hogs were being fed, which was the full capacity of the plant. No brood sows are kept, but pigs weighing about 50 catties $^{8}$ are purchased from the village farmers. Brewer's grains from the distillery form the largest part of the ration fed, although some rice chop and wheat bran is also fed. About 600 catties of dry feed are required in this plant to make 100 catties of gain in weight. The hogs are fed for from 200 to 250 days, and, when sold, weigh from 140 to 200 catties. The size of the hogs when sold and the length of the feeding period depend on the individual hogs and on the market prices and demands.

The price paid for rice chop varies from $\$ 3.00$ to $\$ 4.00$ (local silver *) for 100 catties. Brewer's grains sell for 40 cents for 100 catties. Manure from the plant sells for 30 cents for 100 catties. The price received for the hogs on the market is variable. The average price during the years from 1916 to 1918 was $\$ 20.00$ (local silver) for 100 catties, varying from $\$ 16.00$ to $\$ 24.00$. The prices paid for market hogs depend on the size, condition, and the demand at different seasons. Hogs weighing about 150 catties usually bring the best prices; and the prices are usually higher during the winter than at other times of the year. Stags and sows, even when fat and in good condition sell for about three-fourths the

${ }^{3} \mathrm{~A}$ catty, the common unit of weight in China, is equal to $11 / 3$ pounds avoirdupois. During past two years about $\$ 1.30$ local silver has equalled $\$ 1 \mathrm{U}$. S. currency. 


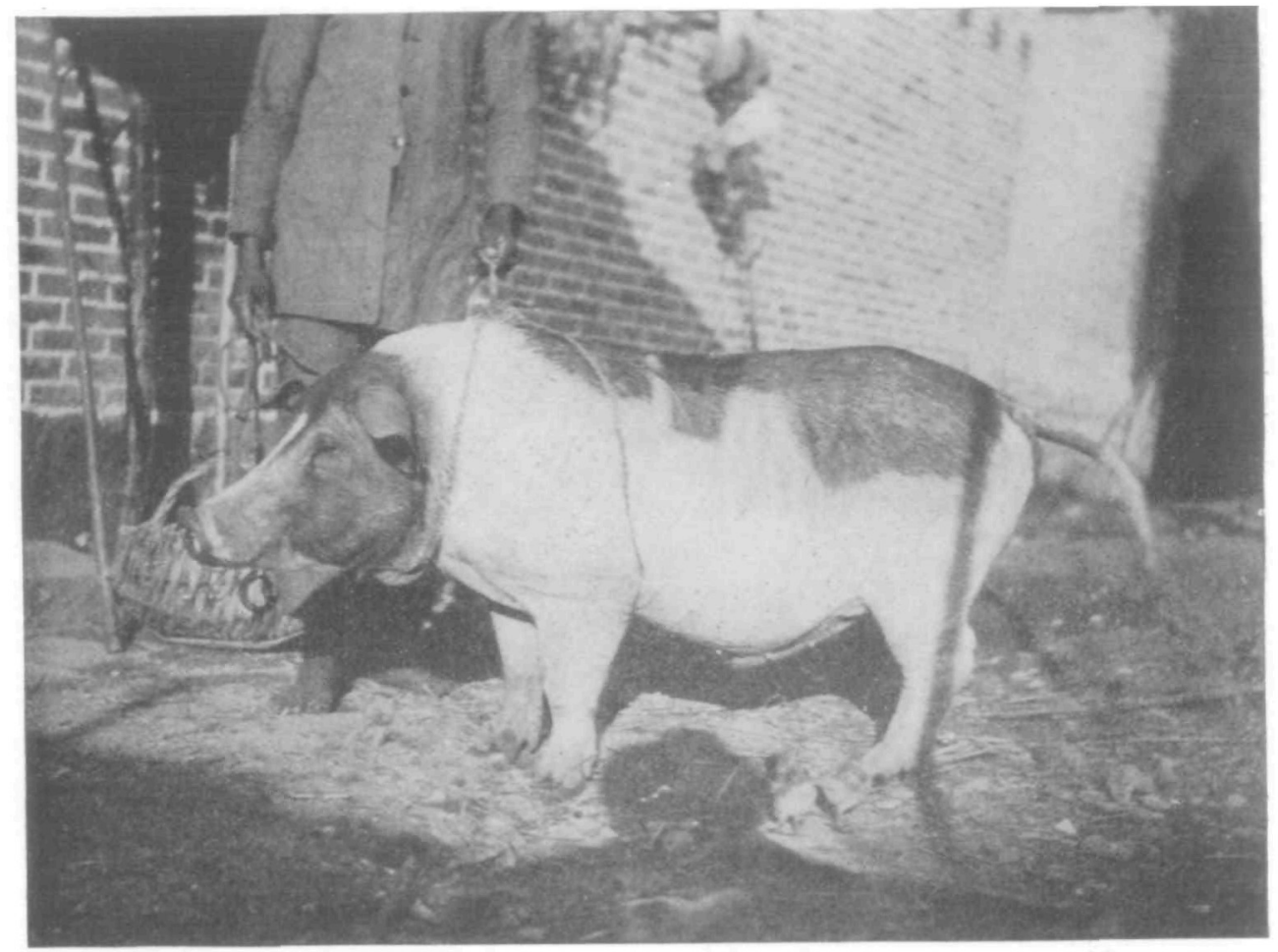

A TYPICAL CHINESE LARD HOG

Chinese hogs vary a great deal in type according to the part of the country from which they come. The straight tail is one of their peculiar characteristics. The usual weight when a year old is from 200 to 250 pounds. (Fig. 14.)

price of good barrows and spayed gilts. Unspayed gilts also sell at a cut price.

The hogs in the plant described above are kept in a brick building across the street from the brewery. They are all kept in one room, about 30 feet wide and 80 feet long. Pens are arranged along the sides of the room with an alley about 6 feet wide in the center. These pens are 12 feet square, and each contains from ten to fourteen hogs. A pen of hogs usually represents one litter. The floor of the entire room is paved with brick tile, sloping from the pens to the alley-way, on either side of which is a gutter. The floor is kept very clean, being washed twice a day, and the pigs themselves get washed in the process of washing out the pens. The solid manure is cleaned from the pens before each washing and stored in a brick and concrete tank at the end of the room where it remains until it is removed by buyers.

\section{THE FEED OF VILLAGE PIGS}

Three times a day the village sow and pigs are fed a mixture of a cheap grade of rice chop and rice bran, and sometimes wheat bran, about the proportion of half and half. Wheat bran is considered a better feed than rice bran, but it is usually higher in price. In the vicinity of breweries, brewer's grain, a by-product of the rice wine industry, forms a part of the ration. Vegetables and green cut grasses are fed. The rice is always fed cooked. Other kinds of feed are uncooked. In regions where corn is as available and cheap as rice, it furnishes the main fattening part of the ration. At night the hogs are kept 


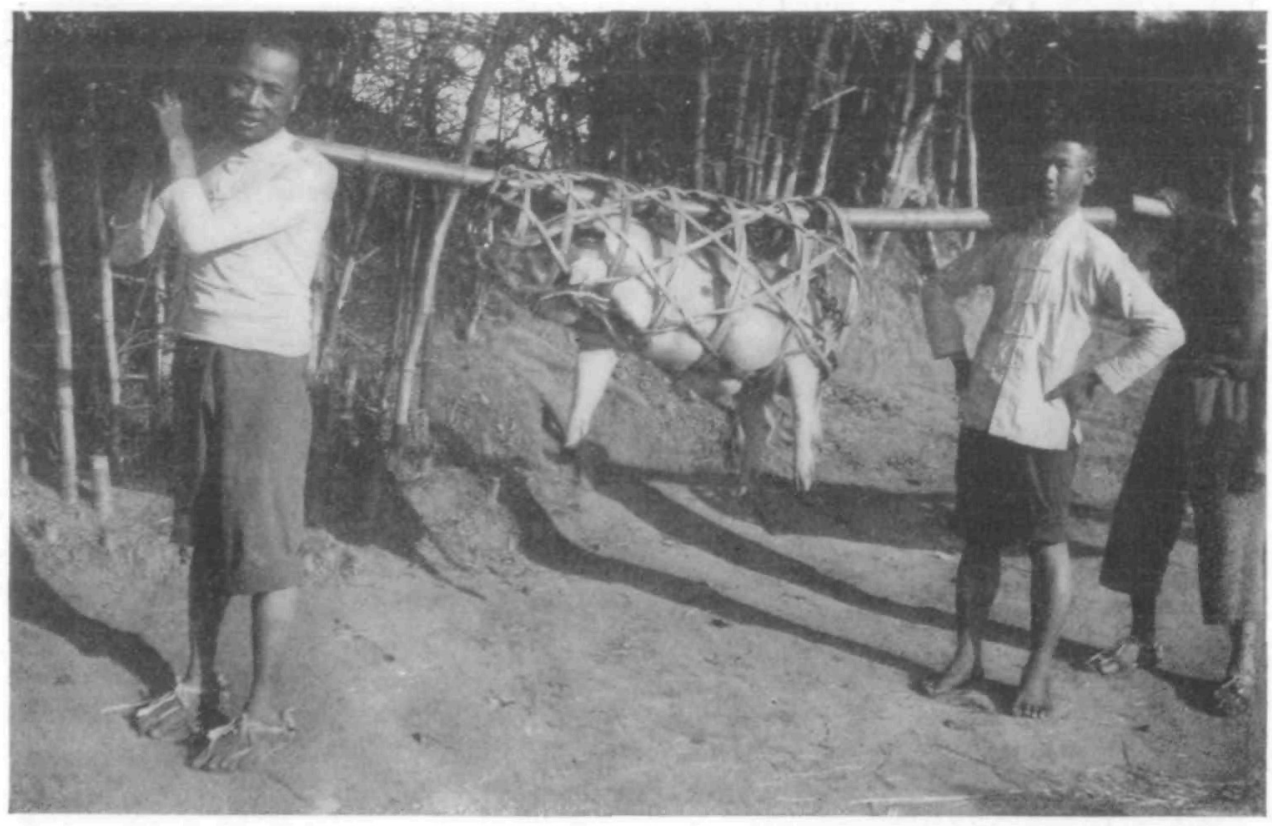

A CHINESE HOG ON ITS WAY TO MARKET (Fig. 15.)

in a room, which is usually next to the owner's living quarters. The floor is usually paved with tile or brick. Sometimes a corner of the living rooms is fenced off for the sow and her family. The floor is usually kept very clean.

From the time they begin to eat, the pigs are given all their feed in the form of a very wet swill. Three times a day they are allowed to drink all they can hold of this feed, which permanently enlarges the belly and tends to pull the animals down in the back. By proper feeding and intelligent selection of breeding stock of the best type, these two undesirable characteristics, swayback and pot-belly, could be remedied.

The average hog in China is raised on as clean food as the hog in America is. It is not a scavenger like the native hogs in India and the Philippine Islands, and it is fairly free from dis. eases, except for hog cholera, which is very prevalent.

\section{FRESH MEAT AND "WATERED MEAT"}

About 1,000 hogs are killed every day in the small Canton butcher shops. The hogs are butchered early in the morning in small slaughter houses and delivered immediately to the retail shops. In some shops the hogs are butchererl in the rear of the retail store, which opens directly on the street.

Dishonest butchers who do not mind putting their reputation at stake have an interesting method of injecting water into the hogs just after they have been killed and bled. The water is forcerl in through the vena cava. The carcas: of a hog may be increased in weight by several pounds by thus "watering" the meat. It is difficult to detect such meat until it is eaten. It has a po.)" flavor compared with normal meat an'l will not cure well. This practice is so general that it is difficult to secure pork in Canton which has not been thus treated.

\section{HOG CHOI.ERA IN CHINA}

Among the diseases of swine, hog cholera, known in England as swine plague, and common in all parts of the world where pigs are raised, is prevalent in all parts of China, where it is known 


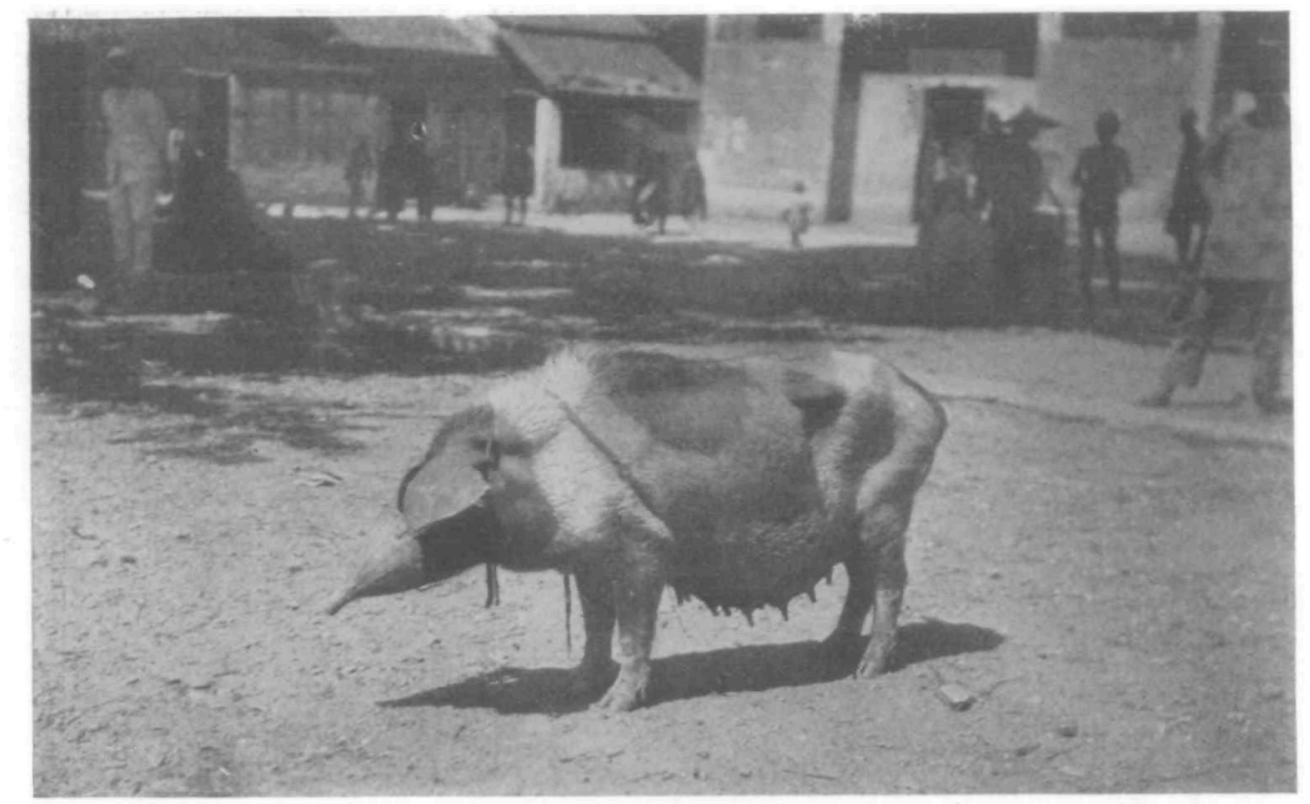

IN A CHINESE VILLAGE STRELT

"During the day the sow and pigs roam at will in the narrow stone streets of the villages picking up what edible garbage they can find. Sometimes, however, the sow is muzzled when thus turned out with her family of pigs." (Fig. 16.)

as Chue Waan. During the months of March, April, and May, it is most prevalent in the south of China. In the delta region of Canton about $40 \%$ of the spring pigs die each year or are marketed because of this widespread disease. The farmers recognize the disease by the characteristic deep red or reddish-purple spots on the abdomen, gummy eyes, spotted kidneys, and inflamed intestines, which are the common symptoms in this region. It $i$; usually accompanied by a high fever. The Chinese have learned by experience that there is no cure for the disease. and know that it is very infectious. It usually proves fatal. Experienced veterinarians, and laboratories for the production of vaccine for the prevention of the disease, are badly needed.

Keeping brood sows to an extreme old age. or until they become sterile, is probably the salvation of the hog industry in China. Such sows have either had mild attacks of cholera when young and have become immune or are highly resistant to the disease, for, according to village farmers, very seldom does a sow more than 3 years old get the disease. Further study is necessary to determine the extent of this natural or acquired immunity. Evidently it is quite common, as none of the old sows observed in the villages surrounding Canton, where cholera rages nearly: every year, have any of the appearance; common to hogs that have recovered from a severe case of cholera.

\section{TUBERCULOSIS AND FARASITES}

Tuberculosis, a disease quite common among hogs and other livestock in America and Europe. gives very little trouble to native livestock of southern China. According to Dr. A. Gibson, who-has been the Colonial Veterinarian of Hongkong for thirteen years, and who has examined the carcasses of thousands of hogs in the government slaughter house, tuberculosis in Chinese hogs is very rare; in cases that have 


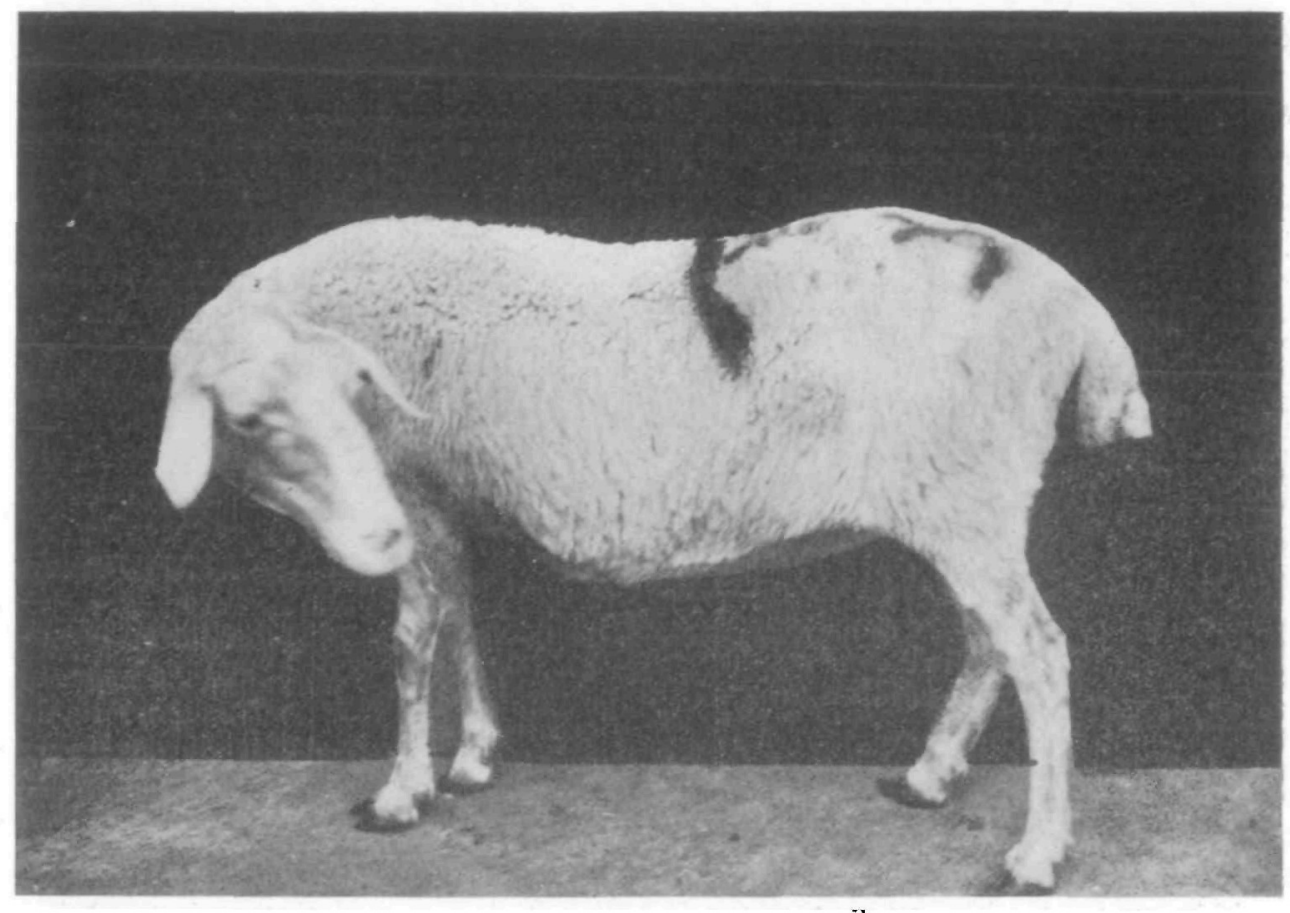

A FAT-TALED SHEEP

This breed of sheep is common in all parts of northern China. The large tail characteristic of this variety contains a very considerable amount of fat and thus the breed has been called the fat-tailed sheep. In arid regions, when food is not plentiful enough, the fat in the tail is drawn on to supply nourishment for the rest of the body. (Fig. 17.)

been observed, they are invariably the animals that have been closely housed with the European hogs. This freedom from disease is indeed fortunate, for tuberculosis is one of the few diseases in animals which we dread, not only because of the effect of the disease on the animal itself, but because of the possibility of its being transmitted to man.

Fewer internal parasites are common in the native hogs than one would expect. A number of tapeworm cysts have been found in nearly every hog we have butchered at the college during the past three years, but, according to Prof. Howard of the Biology Department of the Canton Christian College, they are not the cysts of the tapeworm that is found in man. Dr. Gibson also reports he has not yet found the cyst of the human tapeworm in the native hog. Here again we are fortunate, and great care should be taken not to introduce this parasite from other regions.

Kidney worms and liver flukes, usually common in hogs, have not been found in the hogs of southern China. A skin disease in the form of a pox is very common. It, however, does not seem to be a serious disease. With the exception of cholera, the native hog in South China is, as a whole, a fairly healthy animal.

\section{YUNNAN HOGS}

In the hilly and wooded regions of the western provinces of Yunnan and Szechwan the type of hog chiefly raised is the bacon hog. This type produces a good meat for curing. According to Dr. Gibson, attempts so far to raise this hog in Hongkong have shown that it cannot compete with the common lard hog in the efficiency of utilizing feed. However, if allowed to 


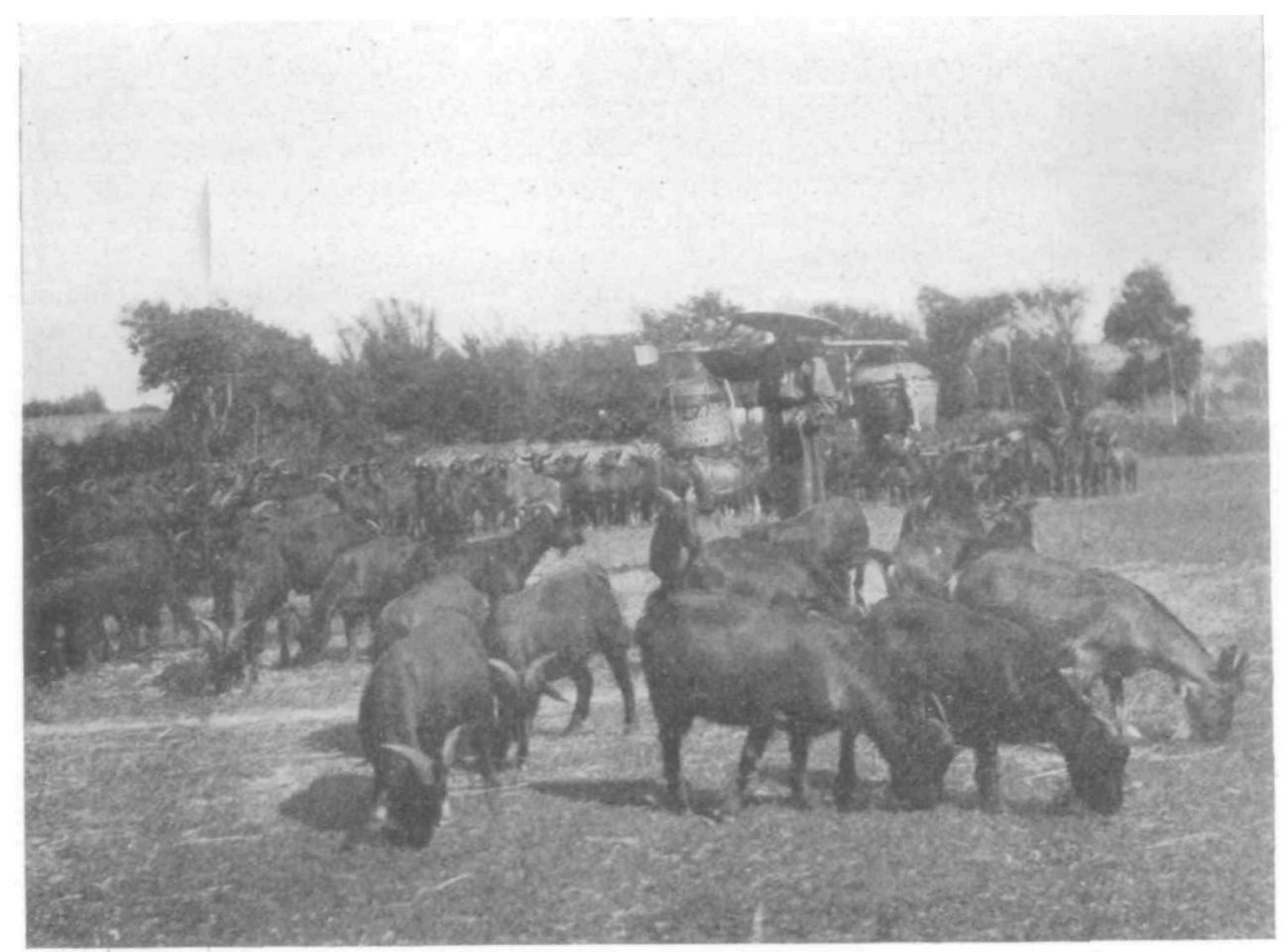

\section{NATIVE GOATS IN SOUTH CHINA}

Goats are raised in China for meat only. Swiss and Indian breeds of milk goats have been introduced into some of the provinces but not to any great extent. (Fig. 18.)

graze, as in Yunnan and Szechwan, it might make a better showing in southern China. The Yunnan ham, found in the Canton and Hongkong shops, and in other parts of China, and exported to the Philippine Islands, is well known in all parts of China because of its excellent qualities.

\section{BREEDING OF SWINE}

One has only to study the breeding stock in the villages about Canton to realize that the average village farmer knows very little about the breeding of animals. Some of the sows are fairly good, but the boars are usually very inferior. About the only good thing that can be said about the boars is that they are sure breeders, and very prolific. The prevalent idea is that any animal is good enough for breeding. Often the poorest male is reserved for stud pur- poses. From the time he is weaned he is kept tied with a sort of rope harness fitted around his neck and chest. $\mathrm{He}$ is lead about from village to village by his owner. On Honam Island, across the river from Canton, one boar is used for from 200 to 300 sows. The boars are always undersized, thin, gaunt and weak looking, but they are unusually gentle and do not have the vicious temperament so commonly seen in boars of improved modern breeds.

\section{MODERN BREEDS OF HOGS IN CHINA}

Modern breeds of hogs have not yet been introduced into China to any extent. The Hongkong Dairy Farm has done considerable experimenting with different breeds, and now uses the Midyorkshire hog of England almost exclusively, both pure and in crossing with the native hogs. The farmer usually 
has on hand from 600 to 900 of this breed of hogs. The Berkshire hog, an English breed whose early development was brought about largely through the use of Chinese and Siamese blooded stock, may prove a success in this climate, as it has done in the Philippine Islands, where most breeds up to the present have been little more than failures. due largely to the readiness with which they succumb to the kidney worm. The Berkshire hogs seem to be able to resist the kidney worm better than any other of the modern breeds. However, as the kidney worm does not seem to be common in China, other breeds may also prove a success.

\section{CHINESE SHEEP AND GOATS}

Sheep.- Sheep of the fat-tailed, hornless variety which is supposed to have criginated in Afghanistan, are found in nearly all parts of northern China, especially in the provinces of Shantung and Chihli. These sheep are so named because of their large tail which carries a large amount of fat. The tail is usually 8 to 10 inches long, 6 inches wide, and 3 inches thick. It serves as a store for food, and in seasons of drought and scarcity of feed the fat contained in the tail is used up in the body. It is said that after a few generations of rich feeding in lands where nourishing feed is more available, the size of the tail gradually diminishes, approaching the size common to other breeds of sheep.

The fat-tailed sheep produce fair wool. though it is inferior in both quantity and quality when compared with that of modern breeds of wool sheep. According to the Japanese investigators in 1916 the annual amount of wool produced in Shantung a mounts to $39,000,000$ pounds. Nost of the wool produced in this region is sold to Japan at about 20 taels a picult, the annual sales amounting to $6,000,000$ taels. The Japanese use most of the wool for making clothing for the soldiers. It is estimated that each sheep will yield in one year with two shearings four catties of wool. At this rate the total number of sheep in Shantung must be at least 7,500,000. The customs authorities give a value of 5 taels a head for sheep. The mature sheep alone in Shantung at this rate have an annual value of $35,000,000$ taels.

Goats.-The native black and white goat of China is raised for meat only. In Shantung a Swiss breed of milk goats, known as the Saanen goat, has been introduced by the Germans. and seems to thrive well in that region. Indians have brought with them to Hongkong an Indian breed of milk goat which is doing well in that region.

SHEEP AND GOATS IN SOUTHERN CHINA

Canton imports from the north 8,000 fat-tail sheep, and 4,000 meat goats for slaughter each year, or at the rate of thirty a rlay. Hongkong also imports in large numbers from the north. Goats of the meat breed are raised to a small extent in South China, but no sheep are raised in the southern provinces. Dr. Adam Gibson, reports that attempts to raise sheep in the south have failed because of the readiness with which they become infested with the liver fluke. Goats butchered at the college in 1917 by the writer were found to be badly infested with this parasite, but evidently the affect on goats is not as serious as with sheep.

\section{REFERENCES AND BIBLIOGRAPHY}

Chinese Customs Reports.

King: "Farmers of Forty Centuries," pp. $3,51,70,135,233$ and 353 .

Report of Military Investigations in Tsingtau, 1916, Shantung Province.

${ }^{5}$ A picul equals $1331 / 3$ pounds. 